\title{
Assessment the Effect of Nitric Oxide on Yield Parameters of Wheat and Maize under Different Levels of Salt Stress
}

\author{
Suryakant Saroj", Anil Dahire, Meghchand Dewangan and Anupama Jain \\ Department of Crop Physiology, Sam Higginbottam Institute of Agriculture, Technology and \\ Science, Naini Allahabad, India \\ *Corresponding author
}

\begin{tabular}{|l|}
\hline Ke y w or d s \\
Salt stress, Maize, \\
$\begin{array}{l}\text { Paddy, Sodium } \\
\text { nitro prusside }\end{array}$ \\
\hline Article Info \\
\hline $\begin{array}{l}\text { Accepted: } \\
\text { 14 December } 2017 \\
\text { Available Online: } \\
\text { 10 January } 2018\end{array}$ \\
\hline \hline
\end{tabular}

A B S T R A C T

Maize (Zea maize) is the 3rd most important cereal world in the world following wheat, rice. It is grown mainly in the semi- arid areas of the tropics and subtropics. Rice (Oryza sativa) is one of the main staples in the world and is cultivated mainly in Asia, Africa, and Latin America. The exogenous application of sodium nitroprusside (SNP), a NO donor, significantly alleviated the oxidative damage of salinity in seedlings of rice enhanced the seedlings growth and increased the dry weight of maize seedlings. In this paper we discus about Plant Nitric Oxide, because now days the plant tolerate the various types of stresses like salt stress, drought stress, cold stress and oxidative stress also. Nitric oxide (NO), a free radical in living organisms, is considered a phytohormone and a key signalling molecule functioning in various physiological processes of plants. These physiological processes include germination, growth, senescence, and photosynthesis as well as response mechanisms to specific environmental stresses. Plants under salt stress conditions experience oxidative and nitrosative stress; the latter mainly elicited by regulation of NO production. Nitrosative stress describes the molecular or cellular damage promoted by imbalance in $\mathrm{NO}$ homeostasis and other reactive nitrogen species. Additionally, depending on its concentration and location in plant cells or tissues, NO might function as an antioxidant and scavenge some other reactive intermediates. Direct or indirect involvement of NO in response mechanisms under water stress, drought, salinity, heavy metal stress, high or low temperature extremities, and ultraviolet radiation has been reported. In this work, the recent findings and current knowledge on the function of $\mathrm{NO}$ in plants under salt stress conditions are reviewed briefly.

\section{Introduction}

Salt-affected soil is one of the serious abiotic stresses that cause reduced plant growth, development and productivity worldwide (Siringam et al., 2011). Addition of salts to water lowers its osmotic potential, resulting in decreased availability of water to root cells.
Salt stress thus exposes the plant to secondary osmotic stress, which implies that all the physiological responses, which are invoked by drought stress, can also be observed in salt stress (Sairam et al., 2002). Growth and yield reduction of crops is a serious issue in salinity prone areas of the world (Ashraf, 2009). Water-deficit and salt affected soil are two 
major abiotic stresses which reduce crop productivity, especially that of rice, by more than 50\% world-wide (Mahajan and Tutejan, 2005; Nishimura et al., 2011). Salinity is one of the important abiotic stresses limiting rice productivity. The capacity to tolerate salinity is a key factor in plant productivity (Momayezi et al., 2009). More than 800 million ha of land throughout the world are salt-affected (FAO, 2008). In many regions of the world and many areas of Iran, salinity stress may occur when crops are exposed to high levels of $\mathrm{Na}$ and $\mathrm{Ca}$ salts. Specific effects of salt stress on plant metabolism, especially on leaf senescence, have been related to the accumulation of toxic $\mathrm{Na}+$ and $\mathrm{Cl}-$ ions and to $\mathrm{K}+$ and $\mathrm{Ca} 2+$ depletion (Al-Karaki, 2000). Salinity associated with excess $\mathrm{NaCl}$ adversely affects the growth and yield of plants by depressing the uptake of water and minerals and normal metabolism (Akhtar et al., 2001; Akram et al., 2001). On the other hand, in arid and semi-arid regions, limited water and hot dry climates frequently cause salinity problem that limit or prevent crop production. At low concentrations, salt suppresses plant growth and at higher concentration can cause death (Michael et al., 2004). It has also been reported that under saline conditions, germination ability of seeds differ from one crop to another and even a significant variation is observed amongst the different varieties of the same crop (Asana and Kale, 1965, Maas and Hoffman, 1977). Maize, which belongs to the plants with $\mathrm{C} 4$ metabolism, is also classified as moderately sensitive to salinity (Mass and Hofffman, 1977; Ouda et al., 2008). For maize grown under salinity, reduction in growth characters and yield were observed (Ouda et al., 2008). As suggested by Souza and Cardoso (2000), a marked increase of germination inhibition is expected at higher $\mathrm{NaCl}$ concen-trations in the substrate. In general, salt stress is directly related with drought stress due to the capacity of the dissolved solutes to retain water.
However, two different mechanisms of salt tolerance enable seeds to germinate at high salt concentrations. Seeds can tolerate the effects of a lower water potential in the substrate (Allen et al., 1983) or they may present specific tolerance to the inhibitory effect of $\mathrm{NaCl}$ (Rumbaugh et al., 1993).

One of the controversies which has caused problems over many years is the way in which NO should be measured in plants. Gupta and Igamberdiev (2013) have contributed an opinion paper and propose that at least two different methods should be used to be sure that NO is truly being measured. This is sound advice and hopefully a strategy that will be adopted by many in the field in the future. D'Alessandro et al., (2013) continue this theme of caution with a paper on the use of cPTIO. This compound is often employed as a scavenger to confirm that $\mathrm{NO}$ is being detected, but it is also used as a means to measure the presence of NO when coupled to electron paramagnetic resonance (EPR). These authors report a systematic investigation into the scavenging of cPTIO and discuss the reliability of such use and as an EPR probe (Baudouin and Hancock, 2013).

Nitric oxide, NO, is a small, water and lipid soluble gas that in recent years has emerged as a major signalling molecule of ancient origin and ubiquitous importance (Durner et al., 1999). In 1992 it was named 'Molecule of the Year' by Science (Koshland, 1992) and since then there has been a huge number of studies on NO biology.

NO emission from plants and its effects on plant growth were described in the early 1970s (Anderson and Mansfield, 1979; Klepper, 1979). However, research on NO and plant signalling was mainly restricted to a few 'pioneers' such as Leshem (Leshem and Haramaty, 1996) and Lamattina (Laxalt et al., 1997) until the two landmark publications in 
1998 describing NO as a plant defence signal (Delledonne et al., 1998; Durner et al., 1998). Since then, studies on NO and plant biology have increased dramatically, with some of this work being reviewed relatively recently (Durner and Klessig, 1999; Beligni and Lamattina, 2001; Wendehenne et al., 2001; Neill et al., 2002b).

Nitric oxide (NO) is a gaseous signalling molecule which has attracted much attention because of its diverse functional roles in physiological processes and response mechanisms to various environmental stresses.

NO functions in cellular protection against toxicity of reactive oxygen species (ROS), defense response, and tolerance to abiotic stress (Lamattina et al., 2003; Corpas et al., 2007; Besson- Bard et al., 2008a; Neill et al., 2008).

In plant cells, endogenous NO can be produced by either L-arginine-dependent nitric oxide synthase (NOS)-like activity or nitrate reductase (NR) activity (Moreau et al., 2008). There are also few other enzymatic and nonenzymatic processes which have been proposed to contribute to cellular NO content. $\mathrm{NO}$ and a family of related molecules are designated as reactive nitrogen species (RNS) which include $S$-nitrosothiols (SNOs), $S$ nitrosoglutathione (GSNO), peroxynitrite $(\mathrm{ONOO}-)$, dinitrogen trioxide $(\mathrm{N} 2 \mathrm{O} 3)$ and nitrogen dioxide (NO2) (Corpas et al., 2007).

\section{Materials and Methods}

Seeds each of Paddy $\left(\mathrm{C}_{3}\right)$ and Maize $\left(\mathrm{C}_{4}\right)$ were procured from SHIATS, Allahabad and University of Agriculture science, Karnataka.

\section{Plant height (cm)}

Plants were selected from each pot. The height of plants was measured from the ground levels up to the tip of plant at 30 days intervals on 30,60and 90 DAS. The average height was then calculated for each observation recorded.

\section{Number of tillers or nodes and internodes /plants}

From plants of each pot, number of tillers/ nodes and internodes were recorded at the maturity stage of the crop.

\section{Harvest index}

For cereals crops, harvest index (HI) is the ratio of harvested grain to total shoot dry matter, and this can be used as a measure of reproductive efficiency.

Harvest index of the plants from each pot was recorded by using the formula given below

Harvest index $=$ - $\begin{gathered}\text { Economical yield } \\ \text { Biological yield }\end{gathered}$

\section{Summary}

The main findings of this investigation are summarized and concluded below:

\section{Plant height at 30 DAS}

The percentage response of nitric Oxide was found highest on P-3546, genotype of Maize at $100 \mathrm{mM} \mathrm{NaCl}$ with $100 \mu \mathrm{M}$ SNP and lower reduction at $100 \mu \mathrm{M}$ SNP also found on Maize with different genotype Macca-3 and better response show on $100 \mu \mathrm{M}$ SNP.

\section{Plant height at 60 DAS}

The percentage response of nitric oxide was found highest on Paddy genotype at $150 \mathrm{mM}$ $\mathrm{NaCl}$ with $100 \mu \mathrm{M} \mathrm{SNP}$ and lower response show both Maize genotype Macca-3 and P3546 at $100 \mu \mathrm{M}$ SNP. 
Fig.1 Effect of nitric oxideon plant height $(\mathrm{cm})$ at 30 DAS of paddy and maize under different levels of salt stress

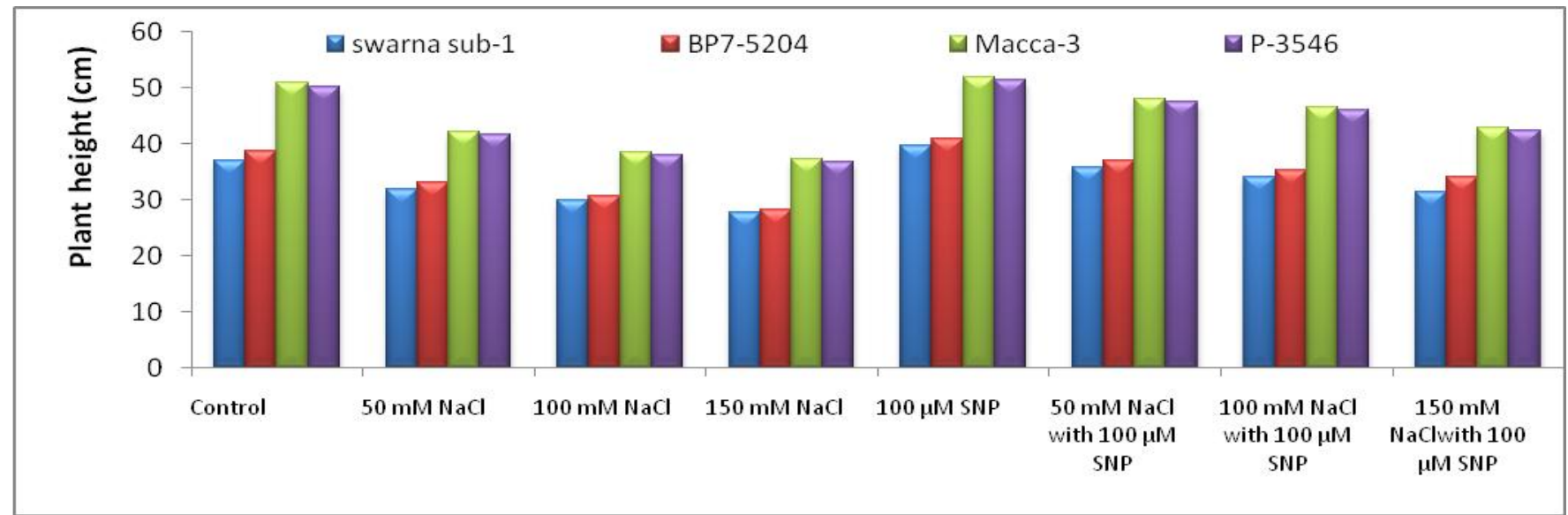

Fig.2 Effect of nitric oxideon plant height $(\mathrm{cm})$ at 60 DAS of paddy and maize under different levels of salt stress

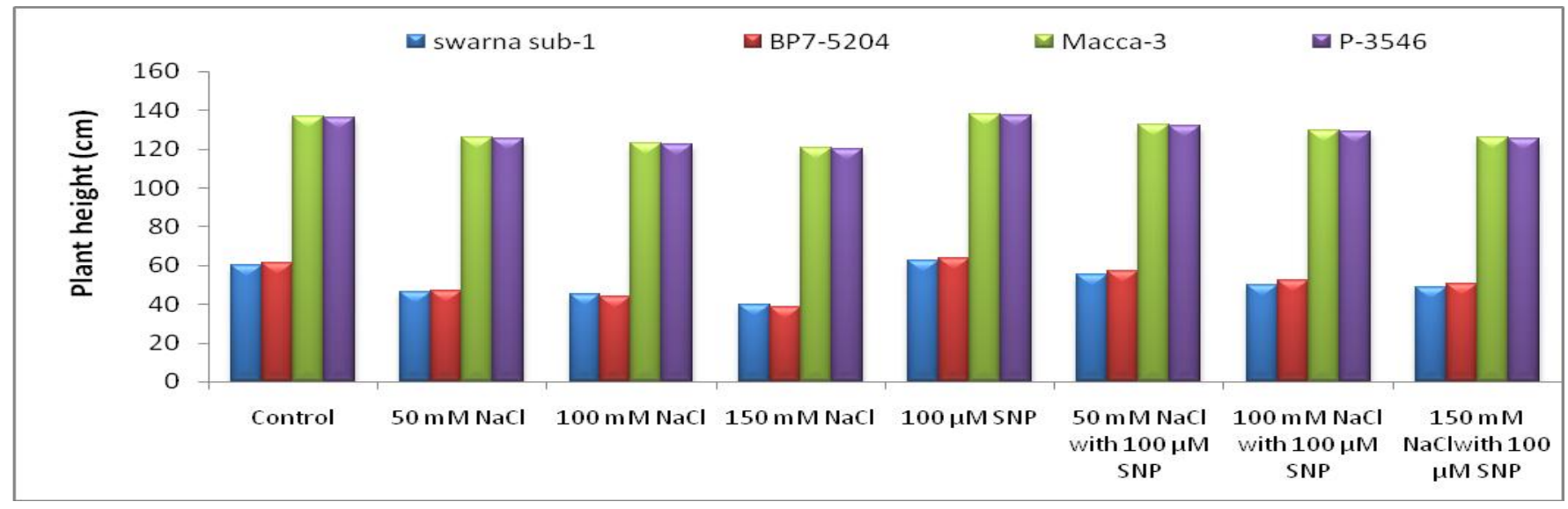

Fig.3 Effect of nitric oxideon plant height $(\mathrm{cm})$ at 90 DAS of paddy and maize under different levels of salt stress

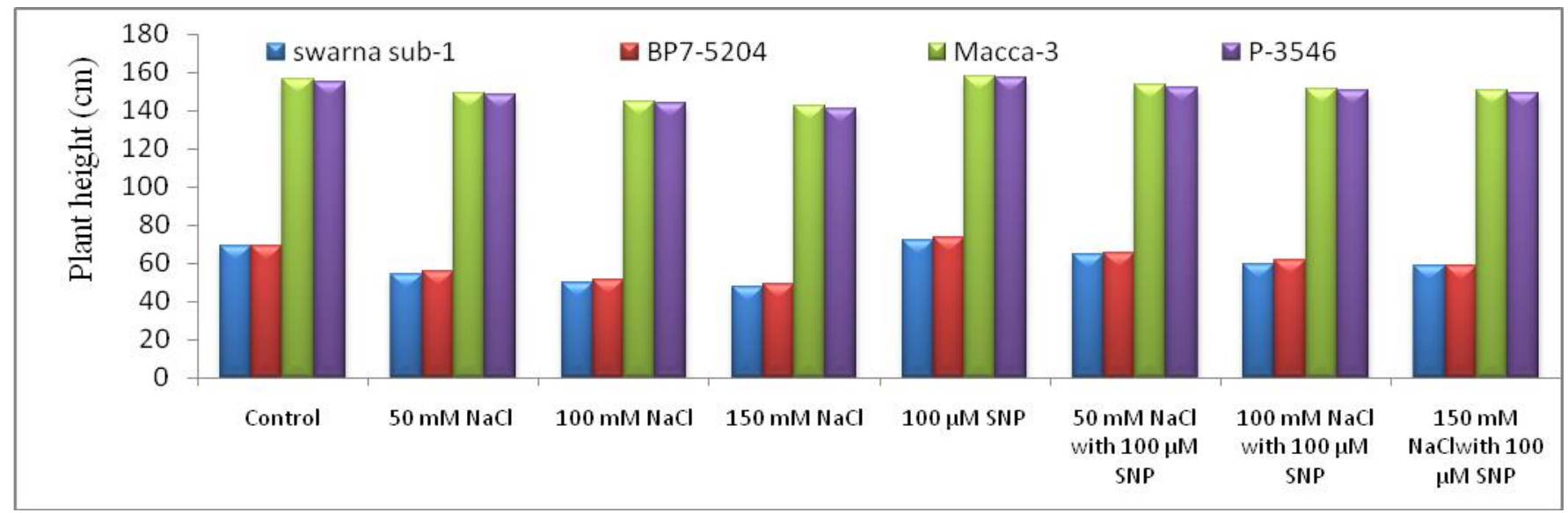


Fig.4 Effect of nitric oxideon No of tillers / nodes at the maturity stage of paddy and maize under different levels of salt Stress

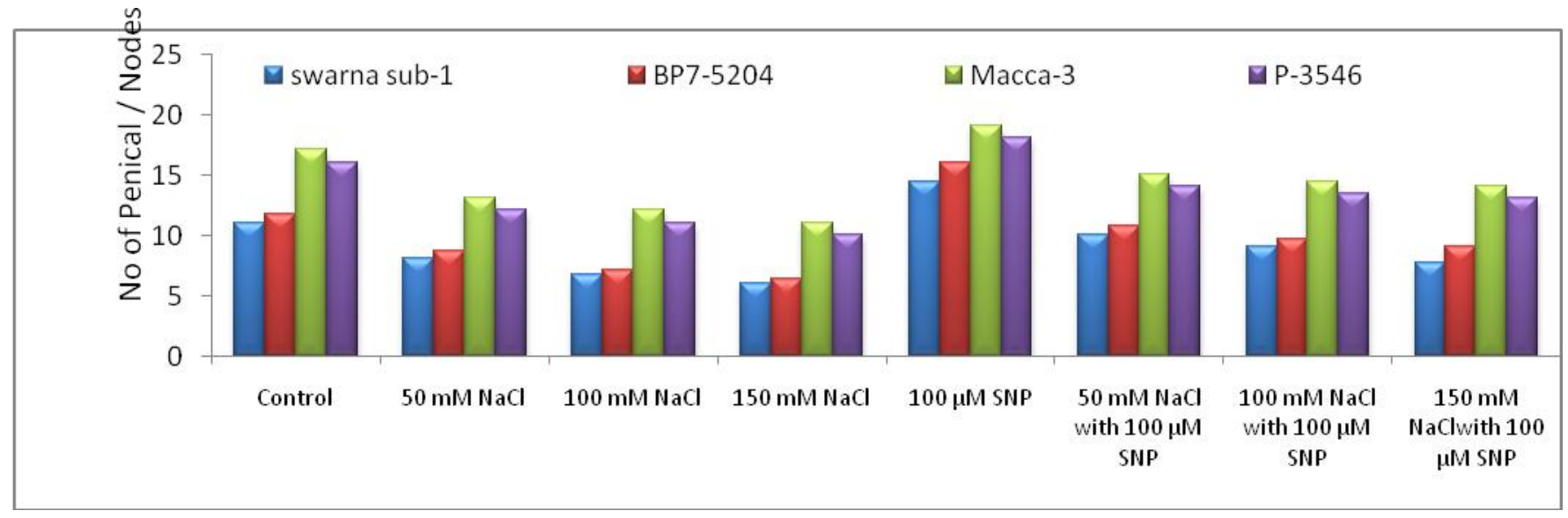

Fig.5 Effect of nitric oxideon harvest index of paddy $t$ and maize under different levels of salt stress

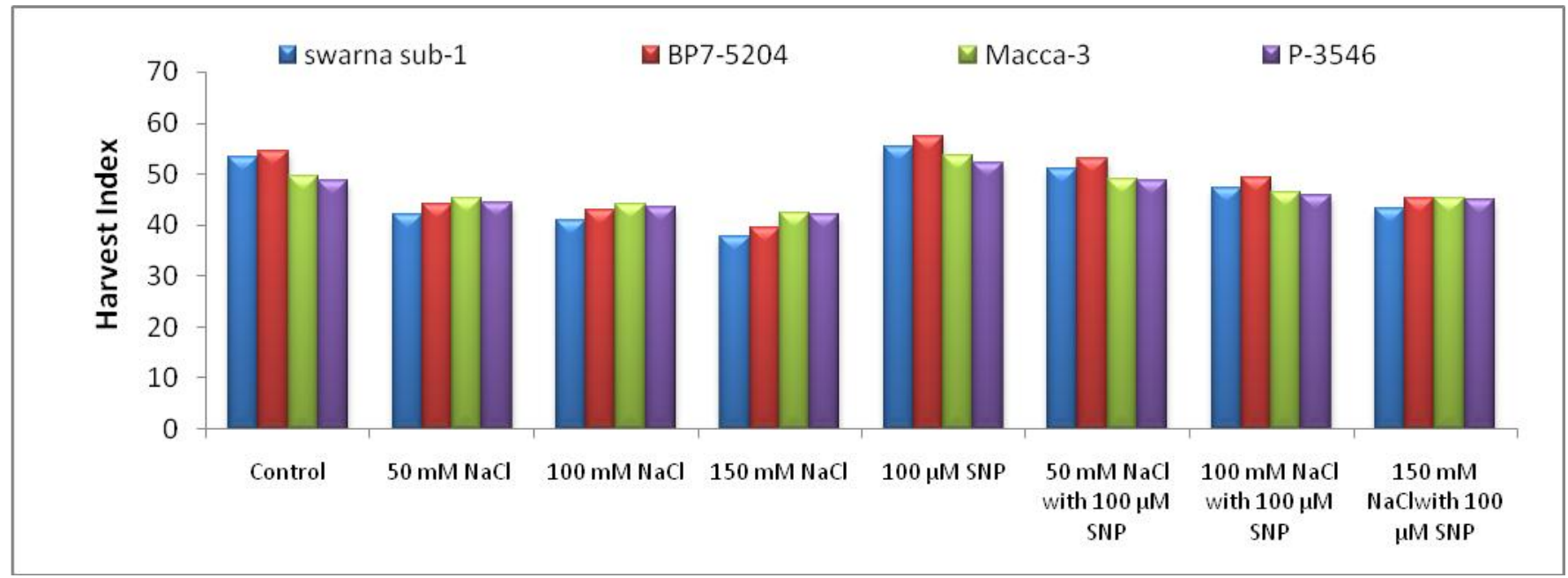

\section{Plant height at 90 DAS}

The percentage response of nitric oxide was found highest on Paddy genotype swarna sub1 at $150 \mathrm{mM} \mathrm{NaCl}$ with $100 \mu \mathrm{M}$ SNP and lower response found on both Maize genotype Macca-3 and P3546 at $100 \mu \mathrm{M}$ SNP.

\section{Harvest Index (\%)}

The percentage response of nitric oxide was found highest on Paddy genotype swarna sub1 at $50 \mathrm{mM} \mathrm{NaCl}$ with $100 \mu \mathrm{M}$ SNP, an d lower response show on Paddy genotype swarna sub-1 at $100 \mu \mathrm{M}$ SNP.

It is well known that abiotic stresses (salinity, water deficit, extreme temperatures, toxic metals, air pollutants etc.) limit plant growth, productivity and yield attribute. Abiotic stress mainly salt stress is estimated to be the primary cause of worldwide crop loss. Several studies have been performed to understand tolerance mechanisms of plants in order to overcome the negative effects of these stresses on yield. There are also studies in 
literature supporting the relevance of NO in plants under salt stress conditions. Application of exogenous NO in different levels of salt stress provides certain level of resistance against several types of stresses by activating different biochemical pathways. NO may help plants to survive stressful conditions through its function as a signalling molecule in the activation of antioxidative enzymes or its direct reaction with active oxygen, nitrogen and lipid radicals. Further genetic and proteomic analyses and additional physiological approaches will be required to understand the details of NO metabolism and function in plants. The acquired data will shed light on the sources of NO Functional Role of Nitric Oxide Under Abiotic Stress Conditions and factors affecting its synthesis under abiotic stress, and also will provide in depth information on different strategies which this multifaceted molecule adopts in facing the detrimental effects of abiotic stress.

\section{References}

Akhtar, S., A. Wahid, M. Akram and E. Rasul, 2001. Effect of $\mathrm{NaCl}$ salinity on yield parameters of some sugarcane genotypes. Int. J. Agr. Biol., 3: 507-509.

Akram, M., M. Hussain, S. Akhtar and E. Rasul, 2001. Impact of $\mathrm{NaCl}$ salinity on yield components of some wheat accessions/varieties. Int. J. Agr. Biol., 4:

Al-Karaki, G.N., 2000. Growth, water use efficiency and sodium and potassium acquisition by tomato cultivars grown under salt stress. J. Plant Nutr., 23: 1-8.

Allen SG, Dobrenz AK, Schonhorst MH, Stoner JE 1983. Heritability of $\mathrm{NaCl}$ tolerance in germinating alfalfa seeds. Agron. J. 77: 99-101.

Anderson L, Mansfield TA. 1979. The effects of nitric oxide pollution on the growth of tomato. Environmental Pollution 20: 113-121.

Asana RD, Kale VR 1965. A study on salt tolerance of four wheat varieties. Ind. J. Plant physiol. 8: 5-22.

Ashraf, M., 2009. Biotechnological approach of improving plant salt tolerance using antioxidants as markers. Biotechnol. Adv., 27: 84-93.

Beligni MV, Lamattina L. 2001. Nitric oxide in plants: the history is just beginning. Plant, Cell and Environment 24: 267278.

Besson-Bard A, Pugin A, Wendehenne D 2008a. New insights into nitric oxide signalling in cGTPase and not a nitric oxide synthase. J Biol Chem 283:32957-32967

Corpas FJ, Carreras A, Valderrama R et al., 2007. Reactive nitrogen species and nitrosative stress in plants. Plant Stress $1: 37-41$

D'Alessandro, S., Posocco, B., Costa, A., Zahariou, G., Schiavo, F. L., Carbonera, D., and Zottini, M. 2013. Limits in the use of cPTIO as nitric oxide scavenger and EPR probe in plant cells and seedlings. Front. Plant Sci. 4, 340.

Delledonne M, Xia Y, Dixon RA, Lamb C. 1998. Nitric oxide functions as a signal in plant disease resistance. Nature 394: 585-588.

Durner J, Gow AJ, Stamler JS, Glazebrook J. 1999. Ancient origins of nitric oxide signaling in biological systems. Proceedings of the National Academy of Sciences, USA 96: 14206-14207.

Durner J, Klessig DF. 1999. Nitric oxide as a signal in plants. Current Opinion in Plant Biology 2: 369-374.

Durner J, Wendehemme D, Klessig DF. 1998. Defense gene induction in tobacco by nitric oxide, cyclic GMP and cyclic ADP-ribose. Proceedings of the National Academy of Sciences, USA 95: 10328-10333.

Ebrahimi Rad H, Aref F and Rezaei M., 2012. Response of Rice to Different Salinity Levels during Different Growth Stages, 
Research Journal of Applied Sciences, Engineering and Technology 4(17): 3040-3047, 2012 ISSN: 2040-7467

Emmanuel Baudouin and John Hancock 2013. Nitric Oxide Signalling in Plants Frontiers in Plant Science Front. Physio. 4:553. doi:10.3389/fpls.2013.00553

FAO, 2008. Land and Plant Nutrition Management Service. Retrieved from: http://www.fao.org/agb/agl/agll/spush/.

Gupta, K. J., and Igamberdiev, A. U. 2013. Recommendations of using at least two different methods for measuring NO. Front. Plant Sci. 4, 58.

Klepper LA. 1979. Nitric oxide (NO) and nitrogen dioxide $\left(\mathrm{NO}_{2}\right)$ emissions from herbicide-treated soybean plants. Atmosphere and Environment 13: 537.

Koshland DE Jr. 1992. The Molecule of the Year. Science 258: 1861.

Lamattina L, Beligni MV, Garcia-Mata C, Laxalt AM. 2001. Method of enhancing the metabolic function and the growing conditions of plants and seeds. US Patent. US 6242384 B1.

Lamattina L, Garcia-Mata C, Graziano M, Pagnussat G 2003. Nitric oxide: the versatility of an extensive signal molecule. Annu Rev Plant Biol 54:109136

Laxalt AM, Beligni MV, Lamattina L. 1997. Nitric oxide preserves the level of chlorophyll in potato leaves infected by Phytophthora infestans. European Journal of Plant Pathology 103: 643651.

Leshem YY, Haramaty E. 1996. The characterisation and contrasting effects of the nitric oxide free radical in vegetative stress and senescence of Pisum sativum Linn. foliage. Journal of Plant Physiology 148: 258-263.

Maas EV, Hoffman GJ 1977. Crop salt tolerance-current assessment. Journal of Irrigation and Drainage Division.
American Society of Civil Engineering. 103: 115-134.

Mahajan, S. and N. Tutejan, 2005. Cold, salinity and drought stresses: An overview. Arch. Biochem. Biophys., 444: 139-158.

Michael D, Peel B, Waldron L, Kevin B 2004. Screening for salinity tolerance in Alfalfa. Crop Sci. 44: 2049-2053

Momayezi, M.R., A.R. Zaharah, M.M. Hanafi and I. Mohd Razi, 2009. Agronomic characteristics and proline accumulation of Iranian rice genotypes at early seedling stage under sodium salts stress. Malays. J. Soil Sci., 13: 59-75.

Moreau M, Lee GI, Wang Y et al., 2008. AtNOS/AtNOA1 is a functional Arabidopsis thaliana plants. Ann Rev Plant Biol 59:21-39

Neill S, Barroso R, Bright J, Desikan R, Hancock J, Harrison J, Morris P, Ribeiro D, Wilson J 2008. Nitric oxide, stomatal closure, and abiotic stress. J Exp Bot 59:165-176

Neill SJ, Desikan R, Clarke A, Hancock JT. 2002a. Nitric oxide is a novel component of abscisic acid signalling in stomatal guard cells. Plant Physiology 128: 13-16.

Neill SJ, Desikan R, Clarke A, Hurst RD, Hancock JT. 2002b. Hydrogen peroxide and nitric oxide as signalling molecules in plants. Journal of Experimental Botany 53: 1237-1242.

Nishimura, T., S. Cha-um, M. Takagaki and K. Ohyama, 2011. Survival percentage, photosynthetic abilities and growth characters of two indica rice (Oryza sativa L. spp. indica) cultivars in response to isoosmotic stress. Span. J. Agric. Res., 9: 262-270.

Ouda SAE, Mohamed SG, Khalıl FA 2008. Modeling the effect of different stress conditions on maize productivity using yield-stress model. Int. J. Natural Eng. Sci. 2(1): 57-62. 
Sairam, R.K., K.V. Veerabhadra Rao and G.C. Srivastava, 2002. Differential response of wheat genotypes to long term salinity stress in relation to oxidative stress, antioxidant activity and osmolyte concentration. Plant Sci., 163: 1037-1046. SAS, 2001. SAS user's guide of release version 8.2.

Siringam, K., N. Juntawong, S. Cha-um and C. Kirdmanee, 2011. Salt stress induced ion accumulation, ion homeostasis, membrane injury and sugar contents in salt-sensitive rice (Oryza sativa $\mathrm{L}$. spp. indica) roots under isoosmotic conditions. Afr. J. Biotech., 10: 13401346. Wiynarah, K., 1990. Growth responses

Wendehenne D, Pugin A, Klessig DF, Durner J. 2001. Nitric oxide: comparative synthesis and signalling in animal and plant cells. Trends in Plant Science 6: $177-183$.

\section{How to cite this article:}

Suryakant Saroj, Anil Dahire, Meghchand Dewangan and Anupama Jain. 2018. Assessment the Effect of Nitric Oxide on Yield Parameters of Wheat and Maize under Different Levels of Salt Stress. Int.J.Curr.Microbiol.App.Sci. 7(01): 1835-1842.

doi: https://doi.org/10.20546/ijcmas.2018.701.223 